\title{
PAISAGEM URBANA DO CENTRO HISTÓRICO DA CIDADE DE JATAÍ (GO): AS RUGOSIDADES CONTAM HISTÓRIA
}

Priscila Braga Paiva

Universidade Federal de Goiás, Jataí, GO, Brasil Programa de Pós-graduação em Geografia, Jataí/UFG-UFJ priscilabragapaiva@gmail.com

Maria José Rodrigues Universidade Federal de Goiás, Jataí, GO, Brasil Programa de Pós-graduação em Geografia, Jataí/UFG-UFJ mariarodrigues@ufg.br

\begin{abstract}
RESUMO
A pesquisa tem como objetivo investigar a existência de rugosidades na paisagem do Centro Histórico da cidade de Jataí (GO). A metodologia, foi estruturada em etapas, sendo elas: Pesquisa bibliográfica e documental, trabalho de campo; análise, interpretação e discussão dos dados coletados. Os resultados mostraram a presença de construções com arquitetura contemporânea, bem como algumas de estilo arquitetônico do final do século XIX e início do século XX. Dessa forma, percebeu-se diversos usos do solo no centro histórico de Jataí, também foi possível identificar que existem poucas edificações da formação inicial da cidade, sendo que, as que ainda resistem, a maioria foram transformadas em museus.
\end{abstract}

Palavras-chave: Paisagem. Espaço urbano. Rugosidade.

\section{PAISAJE URBANO DEL CENTRO HISTORICO DE LA CIUDAD DE JATAÍ (GO): LAS ASPEREZAS CUENTAN LA HISTORIA}

\begin{abstract}
RESUMEN
La investigación tiene como objetivo investigar la existencia de asperezas en el paisaje del Centro Histórico de la ciudad de Jataí (GO). La metodología se estructuró en etapas, a saber: Investigación bibliográfica y documental; trabajo de campo; análisis, interpretación y discusión de los datos recopilados. Los resultados arrojaron presencia de construcciones con arquitectura contemporánea, así como algunas de estilo arquitectónico de finales del siglo XIX y principios del XX. De esta manera, se notaron varios usos del suelo en el centro histórico de Jataí, también se pudo identificar que hay pocas edificaciones en la formación inicial de la ciudad, y las que aún resisten, la mayoría fueron transformadas en museos.
\end{abstract}

Palabras-clave: Paisaje. Espacio urbano. Aspereza.

\section{INTRODUÇÃO}

A categoria de paisagem não é exclusiva da Geografia, porém, possui especificidades para as pesquisas dessa área, sendo bastante utilizada para o estudo das relações humanas e suas interações com o meio.

O estudo da paisagem foi utilizado para o desenvolvimento da pesquisa, sendo necessário entender que se trata de uma categoria dinâmica, que permite a análise em diferentes escalas espaciais e temporais. A paisagem configura-se como algo que carrega consigo elementos do tempo histórico presente, assim como do passado, sendo testemunha de mudanças culturais, arquitetônicas, sociais e econômicas de determinada sociedade. A mesma pode possuir, em um único espaço geográfico: contradições, tempos, formas, cores e aparência em geral diversificada, sendo as rugosidades resultados dessas mudanças que permanecem no espaço.

A partir dessas afirmações, utilizou-se da categoria paisagem urbana, para estudar as transformações espaciais que vêm ocorrendo nos últimos tempos no Centro Histórico de Jataí. 
Por meio do estudo da paisagem urbana do Centro Histórico da cidade de Jataí, e sobre o contexto de centro urbano, é que a presente pesquisa tem como objetivo identificar rugosidades na paisagem urbana do respectivo local.

A pesquisa foi estruturada em quatro etapas, sendo elas: pesquisa bibliográfica, - com discussão do referencial teórico de autores que abordam as seguintes temáticas: paisagem, paisagem urbana, rugosidade, centro, centralidade; pesquisa documental e iconográfica no Museu Histórico de Jataí, trabalho de campo - observação da paisagem do Centro Histórico de Jataí e registros fotográficos do local e por último análise e interpretação dos dados coletados.

O artigo foi estruturado em quatro partes: na primeira apresentamos a introdução, em seguida discutimos a categoria paisagem e paisagem urbana na Geografia, no item seguinte tratamos das rugosidades presentes na paisagem urbana no centro histórico da cidade de Jataí e por último foram apresentadas as considerações finais sobre o estudo.

\section{PAISAGEM E PAISAGEM URBANA NA GEOGRAFIA}

Por ser um tema amplo e com várias interpretações, a paisagem não é uma categoria exclusiva da Geografia, porém, sempre teve relevância nas pesquisas desta ciência, na Geografia tradicional positivista, por exemplo, o que se levava em consideração na categoria de paisagem era a questão natural, que não havia intervenção humana. Para Luchiari (2001, p. 16) as análises da paisagem nesse contexto "sempre estiveram expostas à objetivação analítica do tipo positivista, o que comprometeu, durante muito tempo, uma explicação cultural mais aprimorada".

A geografia tradicional prioriza estudos com abordagem de hipóteses e de valores matemáticos, fazendo com que a questão das relações sociais, como um todo, fosse quase que desprezada. Com as constantes transformações no mundo, houve a necessidade de estudar o meio social e os impactos que este causava/causa no ambiente. Por isso, os estudos sociais começaram a ganhar espaço na academia, inserindo aqui a Geografia. Essa visão crítica na ciência geográfica trouxe consigo uma abordagem do método dialético, enfatizando os contextos sociais e deixando um pouco de lado o método quantitativo.

Nesse sentido, os estudos sobre a sociedade começaram a ser valorizados sendo, às vezes, interpretado como "exclusão" do tradicionalismo geográfico, o qual contribuiu muito para a consolidação dessa ciência, além de ser utilizado até os dias de hoje pelos pesquisadores. Dessa forma, é possível salientar que, atualmente, a paisagem na Geografia é abordada pelos geógrafos de acordo com seu método de pesquisa, ou seja, cabe ao pesquisador definir os elementos da paisagem que irá compor em seu trabalho, sejam eles aspectos físicos ou sociais. De acordo com Pereira (2013, p. 36).

Há na Geografia um tratamento dicotômico sobre a categoria de paisagem, apesar de se tentar unir as duas grandes áreas dessa ciência, quais sejam: a Geografia Física e a Geografia Humana. Alguns geógrafos tendem a trabalhar a paisagem do ponto de vista natural; já outros a discutem a partir da ação antrópica nesse quadro natural, quer dizer, levam a cultura em consideração ao se trabalhar com esse tema.

É possível afirmar que a paisagem se destaca na ciência geográfica desde seus primórdios, e, ao longo dos anos, vem sendo uma categoria de análise que contém variadas formas de estudo. Para Venturini (2008, p. 49).

O termo paisagem e suas derivações (unidade de paisagem, domínio de paisagem, paisagem antropizada, cultural, entre outras) tem sido utilizado com uma certa facilidade, sendo bastante frequente nos trabalhos de pesquisa em Geografia. Essa facilidade advém do fato de haver diversas definições de paisagem, o que atribui ao termo uma certa flexibilidade. É um termo maleável e polissêmico cujo significado pode sem maiores problemas caracterizar qualquer área de estudo em qualquer escala de trabalho, obviamente dentro de um dimensionamento territorial aceito pela Geografia.

A partir da visão crítica acerca do espaço, pode ser afirmado que a paisagem não é composta apenas por aquilo que está à frente dos olhos, ou tudo aquilo que se vê, mas também pelo que se esconde na sua essência. Segundo Souza $(2013$, p. 46) "a paisagem é uma forma. Uma aparência. O conteúdo por trás da paisagem pode estar em consonância ou em contradição com essa forma e com o que ela, por hábito ou ideologia, nos sugere". 
Nessa perspectiva, para escolher a paisagem como categoria de análise para a pesquisa, é necessário entender que se trata de utilizar uma abordagem dinâmica, com diversas escalas de tempo e de níveis de observação. Para Santos (2007, p. 54).

[...] a paisagem nada tem de fixo, de imóvel. Cada vez que a sociedade passa por um processo de mudança, a economia, as relações sociais e políticas também mudam, em ritmos e intensidades variados. A mesma coisa acontece em relação ao espaço e à paisagem que se transforma para se adaptar às novas necessidades da sociedade.

Dessa forma, a paisagem configura-se como espaço dinâmico, que, conforme for evoluindo os tempos, se transforma de acordo com as necessidades da sociedade. Todavia, é relevante dizer também que tal paisagem possui, em um único espaço, contradições, tempos, formas, cores e aparência em geral diferentes. Luchiari $(2001$, p. 19) ressalta que a paisagem é, ao mesmo tempo, "ancorada no solo, modelada pelas transformações naturais e pelo trabalho do homem, e, acima de tudo, objeto de um sistema de valores construído historicamente e apreendido diferentemente no tempo e no espaço, pela percepção humana".

Seguindo essa concepção, estudar a paisagem é um desafio que irá abranger a compreensão das transformações ocorridas no espaço, bem como sua dinamicidade. Nesse sentido, usando a perspectiva crítica da categoria paisagem, pode-se afirmar que ela configura-se como dinâmica, e, de acordo com Melo (2001, p. 32), numa concepção da Geografia cultural, para analisar a paisagem é preciso que os geógrafos procurem "referência nas humanidades, adotando como base as filosofias do significado, especialmente a fenomenologia e o existencialismo".

A partir dessa afirmação sobre a paisagem e sua dinâmica, utilizou-se da paisagem urbana como exemplo das transformações espaciais que vêm ocorrendo nos últimos tempos no centro histórico de Jataí. Para Carlos (2009, p. 38) "a paisagem não é só produto da história, como também reproduz a história, a concepção que o homem tem e teve do morar, do habitar, do trabalhar, do comer e do beber, enfim, do viver".

A paisagem urbana está associada a um conjunto de objetos que têm idades diferentes, mostrando a heterogeneidade do espaço que se encontra a cidade. Na cidade, encontram-se diferentes construções, espaços públicos, comércios, dentre outras características que são visíveis na paisagem. Carlos (2009, p. 35) aponta que

[...] podemos perceber que essas construções não são iguais do ponto de vista arquitetônico, datam de tempos diferentes. Há bairros mais novos e mais velhos. Há prédios de pastilha, outros envidraçados. A dimensão de vários tempos está impregnada na paisagem da cidade. É o ritmo de vida. O modo de expressão da vida na cidade. Ruídos diversos.

A diversidade no espaço urbano é resultado das ações humanas diante de suas necessidades. Em um mesmo espaço, é possível observar uma paisagem contraditória e complexa, onde bairros "pobres" e "ricos" são separados por um muro, ou uma rua. Construções modernas ao lado de construções de séculos passados. Diversas formas e funções no mesmo espaço geográfico.

Carlos (2009, p. 49) destaca sobre a dinâmica da paisagem, que, "dependendo da hora do dia, ou do dia da semana, a observação de uma determinada paisagem vai mostrar um determinado momento do cotidiano da vida das pessoas que moram, trabalham e se locomovem num determinado lugar. É o tempo da vida". Conforme vai passando o tempo, e o modo de viver da sociedade se modificando, a paisagem ganha novas cores e matizes, novos elementos e é reproduzida de acordo com as necessidades humanas (CARLOS, 2009). Tal paisagem urbana pode nos mostrar sua aparência, e, ao mesmo tempo, "esconder" sua essência.

Nesse contexto diversificado, é importante ressaltar os elementos da paisagem urbana. Para Carlos (2009, p. 40), observar a paisagem urbana "depreende-se dois elementos fundamentais: o primeiro diz respeito ao 'espaço construído', imobilizado nas construções; o segundo diz respeito ao movimento da vida". Além das estruturas arquitetônicas, é pertinente colocar em questão o fluxo de pessoas, pois este também faz parte da paisagem. Por exemplo, uma avenida é bastante movimentada durante o dia e à noite ela é praticamente vazia. Temos, então, diferentes paisagens a serem observadas. Claro que este é um dos tantos exemplos que poderiam ser citados também.

Essa dialética que compõe a paisagem do espaço urbano é surpreendente. Os contrastes do "novo" com o "velho" em um mesmo espaço, o fluxo de pessoas que muda com o passar das horas, os diferentes modos de viver e as diferentes necessidades dos indivíduos, enfim. A cidade é essa heterogeneidade. Conforme Santos (2014, p. 73) "uma paisagem é uma escrita sobre a outra, é um conjunto de objetos que têm idades diferentes, é uma herança de muitos diferentes momentos".

Nesse sentido, Damiani (2002, p. 161) afirma que "é preciso incorporar ao espaço urbano a crítica da vida cotidiana, que põe acento na reprodução das relações sociais". Ou seja, para compreender a

$\begin{array}{lllll}\text { Caminhos de Geografia } & \text { Uberlândia-MG } & \text { v. 21, n. } 78 & \text { Dez/2020 } & \text { p. 227-236 Página } 229\end{array}$


paisagem urbana, é preciso também analisar as relações sociais que estão configuradas naquele espaço. É da união dos contrários, presente no mesmo espaço que resultará a complexidade da cidade.

Tudo aquilo que se vê na paisagem pode ser interpretada de diferentes formas pelos indivíduos. Segundo Santos (2014, p. 68), nossa tarefa é a de "ultrapassar a paisagem como aspecto para chegar ao seu significado". Dessa forma, a paisagem das cidades se modifica conforme a necessidade da sociedade, por isso, é preciso ir além da forma e aparência da paisagem e, assim, alcançar na sua essência, a contradição e o movimento que estão por trás.

\section{AS RUGOSIDADES CONTAM HISTÓRIA: EXEMPLOS ENCONTRADOS NA PAISAGEM URBANA NO CENTRO HISTÓRICO DA CIDADE DE JATAÍ (GO)}

Os centros das cidades são considerados espaços de multifuncionalidades pois conforme Machado (2013, p. 165), o centro é,

[...] sem sombra de dúvida, o espaço da cidade com maiores marcas da atividade humana na paisagem. É, portanto, o lugar de maiores evidências do passado. Ao longo da evolução histórica, a incidência da técnica modifica substancialmente o espaço central da cidade, transformando as materialidades em formas geográficas com vida econômica e social.

Nos centros das cidades é possível encontrar diversas formas espaciais, usos e funções. Machado (2013, p. 165) afirma que o centro "caracteriza-se pela expressão territorial da área, e está em constante transformação, não apenas de formas materiais, mas também imateriais, que é o que dá vida e movimento, sendo o centro o seu conteúdo simbólico".

Nesse local das cidades, é comum perceber a grande dinamicidade que acontece nos vários momentos do decorrer dos dias. Geralmente, ela é caracterizada por ser uma mancha de comércio que se destaca das demais localidades do espaço urbano.

Sposito (2001) destaca o centro tradicional, que é aquele localizado na área central das cidades, como um exemplo de "centralidade cambiante", a qual é caracterizada pela diferenciação entre os dias e horários de funcionamentos de estabelecimentos comerciais e de serviços. Esse termo usado pela autora é para explicar que essa centralidade não resulta apenas das relações entre localização e fluxos espaciais, mas de suas variações no decorrer do tempo.

Nesse sentido, é possível afirmar que a paisagem é formada pelos elementos do passado e do presente. A compreensão da organização espacial, bem como sua evolução, só se torna possível mediante a acurada interpretação do processo dialético entre formas, estrutura e funções através do tempo. (SANTOS, 2014)

A presença de construções de épocas passadas nos centros urbanos revela que o espaço é produzido e reproduzido constantemente, e que as funções se modificam de acordo com as necessidades que estão impostas na atual sociedade capitalista, por isso, realizar estudos sobre as transformações da paisagem urbana, com ênfase no centro urbano tradicional, é importante para compreender o processo histórico e geográfico do local. Na figura 1 é possível verificar o núcleo urbano em 1908 e a configuração da cidade de Jataí em 2020.

Figura 1 - Cidade de Jataí: delimitação do Centro Histórico (núcleo originário) e a configuração urbana em 2020.

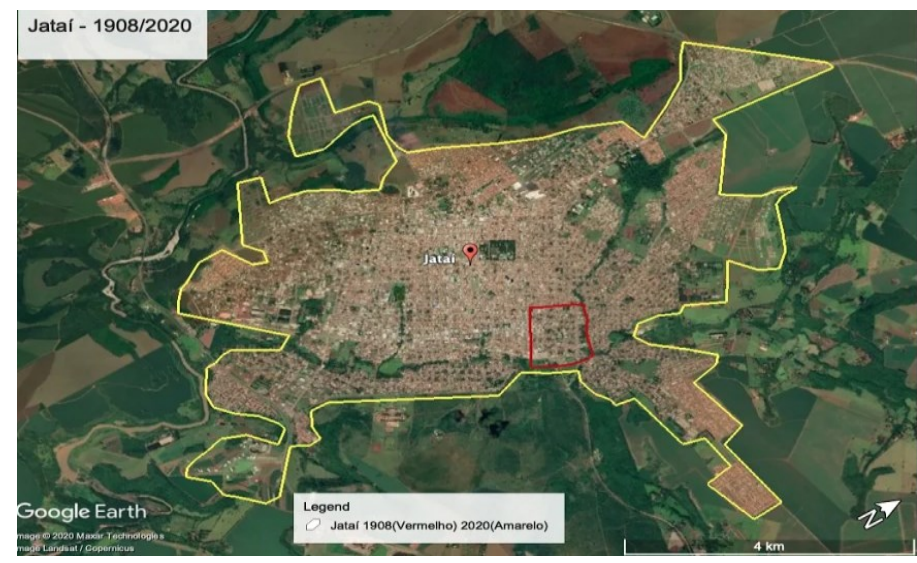

Fonte - Google Earth, 2020. Organização: SILVA, M.R, 2020. 
O núcleo originário da cidade passou por várias transformações socioespaciais ao longo dos anos. As ruas que antes eram de terra, passaram a ter paralelepípedos e, em seguida, asfalto. Os casarões antigos, com arquitetura característica do final do século XIX e início do século XX, foram perdendo espaço frente às construções, mais modernas. Os espaços públicos, como as praças, foram sendo modificados, o fluxo de veículos aumentou, dentre outros aspectos que evidenciam que o espaço se modifica de acordo com as necessidades da sociedade.

As rugosidades podem ser encontradas na paisagem urbana das cidades como forma de demonstrar o processo histórico de transformação socioespacial de uma estrutura urbana. De acordo com Santos (2014, p. 140) o uso deste termo serve para identificar

[...] ao que fica do passado como forma, espaço construído, paisagem, o que resta do processo de supressão, acumulação, superposição, com que as coisas se substituem e acumulam em todos os lugares. As rugosidades se apresentam como formas isoladas ou como arranjos.

As rugosidades mostram parte do que era composto no passado e revelam combinações que eram características de certo tempo e lugar. Nessa perspectiva, analisar a paisagem das cidades é uma importante forma para estudar as transformações socioespaciais de determinado local. Para Alves, (2016, p.52) "a rugosidade é pensada e percebida através do sistema de objetos e ações dos vários agentes que constroem sentido de cidade e seu patrimônio".

Ainda para Alves (2016,p.52)

[...] a rugosidade revela no contexto da ciência geográfica ao longo do processo histórico significados e diferenças, além das manifestações de um modo de vida dominante [...], mas também considera as manifestações da cultura na sua totalidade dando relevância à vida e às experiências da sociedade.

Dessa forma, por meio dos dados coletados, foi possível identificar as rugosidades presentes na paisagem urbana jataiense, principalmente no Centro Histórico, visto que, essa área foi onde ocorreram as primeiras ocupações do núcleo urbano. Estudá-las nos trouxe a reflexão sobre as transformações na organização do espaço de Jataí motivadas pelo uso e pelo progresso das técnicas, o que possibilita o conhecimento da paisagem e do sistema de movimento dessa sociedade.

Para Santos (2014, p.43) "através dos objetos, a técnica é história no momento da sua criação e de sua instalação e revela o encontro, em cada lugar, das condições históricas (econômicas, socioculturais, políticas e geográficas)".

Isso explica a presença de construções de tempos passados, sendo essas formas isoladas, que estão sendo utilizadas como museus, principalmente. Tais construções são destacadas por terem características coloniais, e, de acordo com Pinto Júnior, Menezes e Silva (2012, p. 31) "essas casas urbanas seguiram, de modo geral, a tipologia das casas térreas bastante comuns em todo Brasil, muitas vezes aproveitando o desnível do terreno para porões ou depósitos".

As estruturas arquitetônicas apresentam algumas particularidades inerentes ao estilo arquitetônico muito comum às construções residenciais de até meados do século $\mathrm{XX}$, como, por exemplo, as casas com grandes portas e janelas, a ausência de espaços para garagem, denotando o período em que era pouco frequente a presença do automóvel, a ausência de muros separando uma casa da outra, dentre outros aspectos da época. De acordo com Pinto Júnior, Menezes e Silva (2012, p. 31), "a formação da arquitetura residencial no sudoeste de Goiás seguiu o esquema básico configurado a partir da colonização no Brasil. A particularidade de Jataí se revela na identificação das influências que configuram tanto sua arquitetura quanto seu espaço urbano".

Desse modo, a partir dessas considerações, é possível afirmar que, ao longo dos anos, houve diversas transformações na paisagem da cidade, pois, tudo se modifica de acordo com as necessidades da sociedade. Para Santos (2007, p. 36) "o espaço, considerado como um mosaico de diferentes eras sintetiza, de um lado, a evolução da sociedade e explica, de outro lado, situações que se apresentam na atualidade".

Nesse sentido, a partir do trabalho de campo, foi possível identificar a presença de algumas rugosidades na cidade de Jataí (conforme figura 2). É importante ressaltar que, durante a coleta dos dados foram observados vários aspectos que compõem a paisagem na qual estão inseridos esses contrastes do "velho" com o "novo", como por exemplo, como são as construções, as ruas e o fluxo de veículos e pedestres, na área de estudo. Também foi investigado sobre o histórico da funcionalidade das construções antigas.

$\begin{array}{lllll}\text { Caminhos de Geografia } \quad \text { Uberlândia-MG } & \text { v. 21, n. } 78 & \text { Dez/2020 } & \text { p. 227-236 Página } 231\end{array}$


Figura 2 - Localização dos pontos coletados na Área Urbana de Jataí.

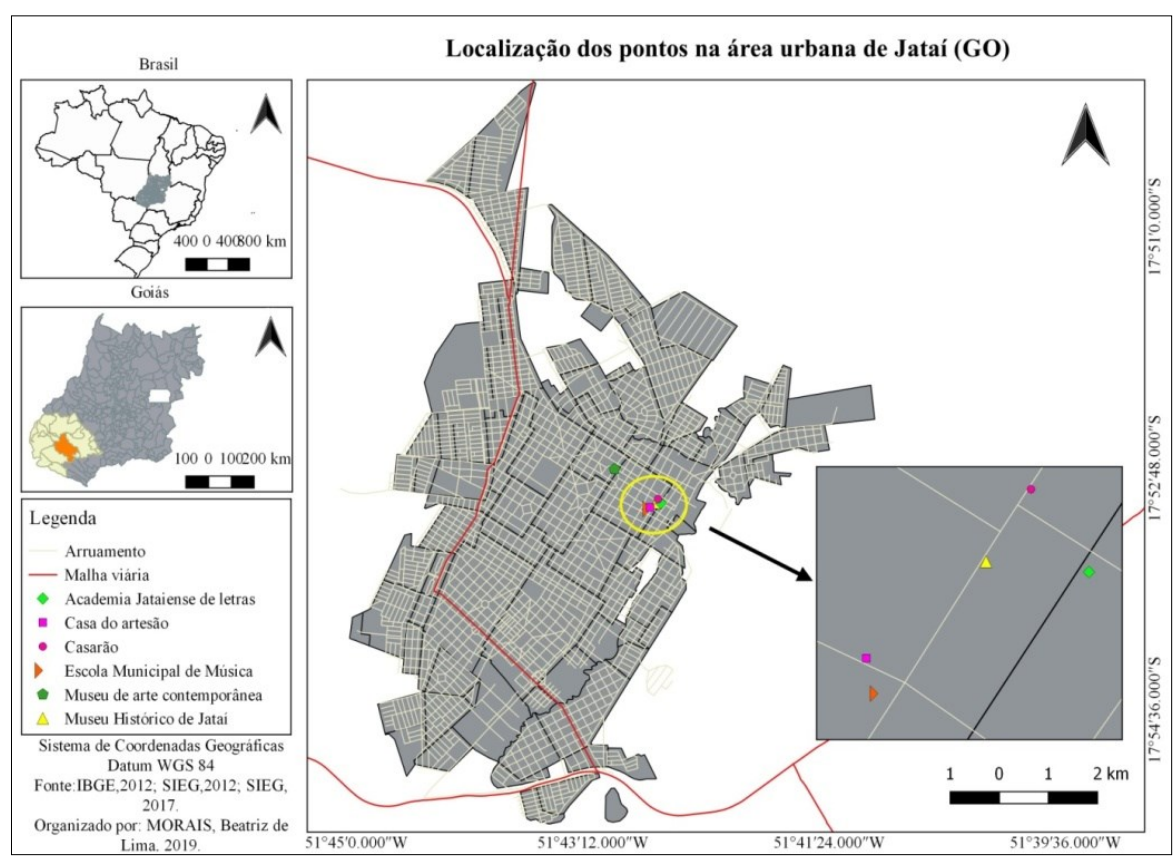

Fonte - IBGE, 2012. SIEG, 2012. SIEG, 2017. Organização: MORAIS, B. de L, 2019.

Na Avenida Moisés Santana, no Centro Histórico, está situada a Academia Jataiense de Letras (figura 3). Este casarão, construído no final do século XIX, é uma das primeiras residências de Jataí, a qual, pertenceu a José Manoel Vilella, conhecido como o grande fundador da cidade. Com o passar dos anos, sua função foi se modificando, além de casa, a construção também foi colégio e hoje em dia é a sede da Academia Jataiense de Letras. Nota-se que foram feitas adaptações em sua estrutura para poder preservar a construção. Uma observação interessante constatada é que as casas (conforme a figura 3) possuem uma estrutura sem recuo do terreno e com ausência de garagem, sendo algo característico da arquitetura colonial, o que se destaca como diferencial entre as formas arquitetônicas da contemporaneidade.

Figura 3 - Centro Histórico de Jataí (GO): Academia Jataiense de Letras, localizado Avenida Moisés Santana e Casarão, localizado na Rua José Manoel Vilella.

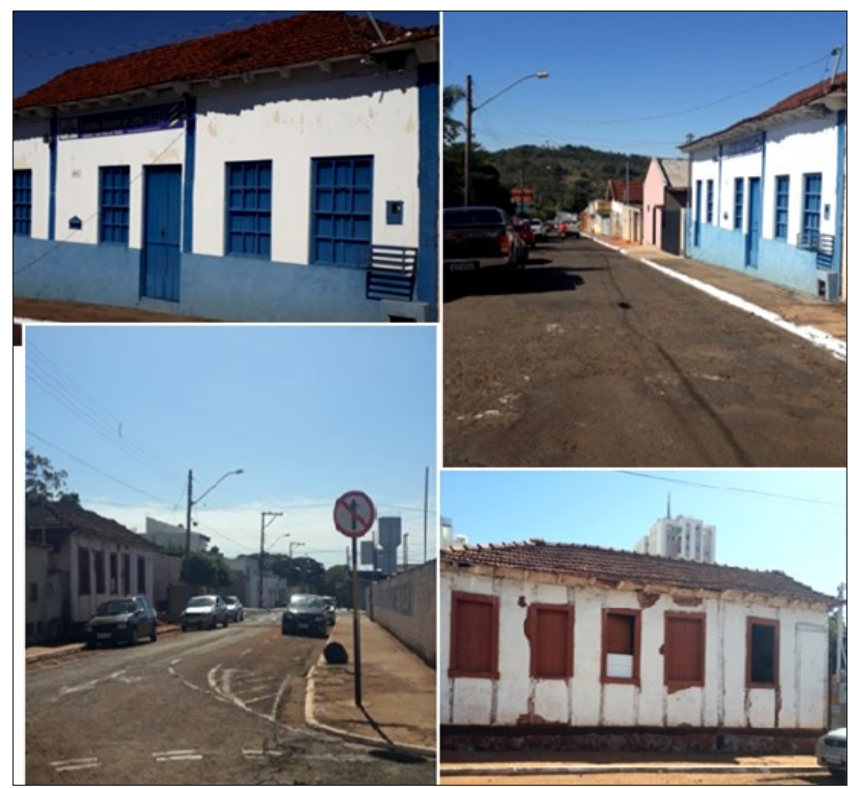

Fonte - PAIVA, P. B, 2018. 
Na mesma rua, também está localizado o Museu Histórico de Jataí - Francisco Honório de Campos, um importante edifício do ano de 1885. Este prédio era residência do Francisco Honório de Campos, que também foi um dos primeiros moradores da cidade, e com o passar dos anos, as funções foram se alterando. Este local já foi, além de casa, escola e espaço de cultura. Atualmente, possui a função de Museu Histórico, e sua estrutura passou por inúmeras adaptações a fim de preservá-la, visto que, este casarão é considerado um dos mais importantes que remete à história da cidade. É testemunha das manifestações de um momento da história do mundo, onde a técnicas de construção da época permitiram, torná-lo uma herança para toda a sociedade jataiense.

Na Avenida Brasil, está localizada a Escola Municipal de Música - Nestor Garcia de Assis (figura 4). Quando este prédio foi construído, no final do século XIX, nele funcionou a primeira sede da Prefeitura Municipal de Jataí, e hoje, é a Escola Municipal de Música, estando localizada em uma importante avenida comercial da cidade.

Figura 4 - Centro Histórico de Jataí (GO): Escola Municipal de Música Nestor Garcia de Assis e Casa do Artesão - ambos localizados na Avenida Brasil, uma das principais vias do Centro Histórico da cidade.

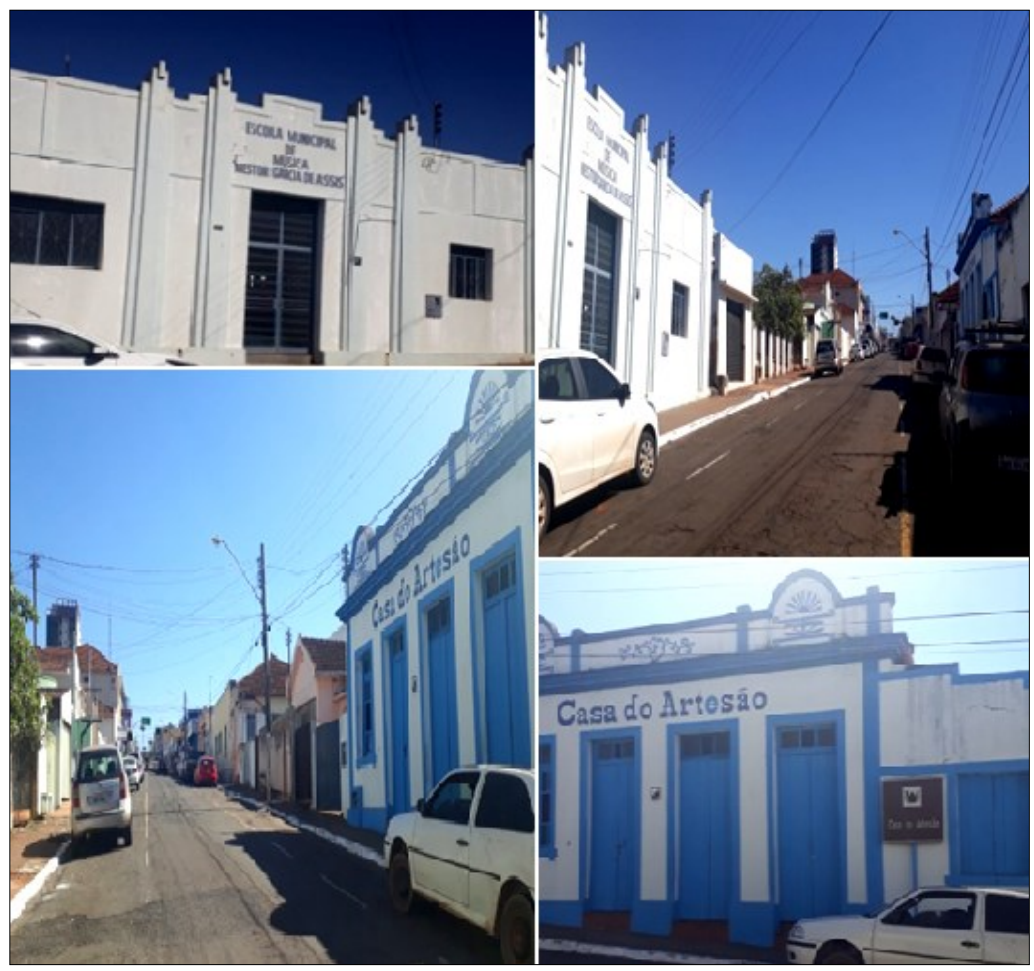

Fonte - PAIVA, P. B, 2018.

Também situada na Avenida Brasil, está a Casa do Artesão (figura 4). Este prédio está localizado em frente à Escola Municipal de Música. Uma importante construção do ano de 1910 que tinha a função de residência de um farmacêutico, além de ser também farmácia e laboratório. Atualmente, possui a função de Casa do Artesão, onde há venda de produtos artesanais feitos por artesãos do município de Jataí.

Na Rua Castro Alves localiza-se o Museu de Arte Contemporânea de Jataí (figura 5), o qual se situa próximo ao bairro Setor Central - Parte Baixa. Este edifício foi construído no ano de 1893 por um libanês chamado Alexandre Gabriel Alfaix, que era importante representante comercial nesta época, a fim de ser loja para atender os fazendeiros da cidade e da região. Além disso, também se tornou moradia de sua família, e, atualmente, é um dos patrimônios da cidade, sendo Museu de Arte Contemporânea, o qual possibilita exposições de artistas locais, regionais e nacionais, além de diversos festivais e workshops para a população. Ao longo dos anos foram feitas adaptações em sua estrutura a fim de conservá-la. Este casarão é muito conhecido na cidade por ter localização que favorece sua visualização, visto que ele se encontra em um bairro próximo ao centro da cidade.

$\begin{array}{lllll}\text { Caminhos de Geografia } & \text { Uberlândia-MG } & \text { v. 21, n. } 78 & \text { Dez/2020 } & \text { p. 227-236 Página } 233\end{array}$ 
Figura 5 - Centro Histórico de Jataí (GO): Museu de Arte Contemporânea de Jataí, localizado na Rua Castro Alves.

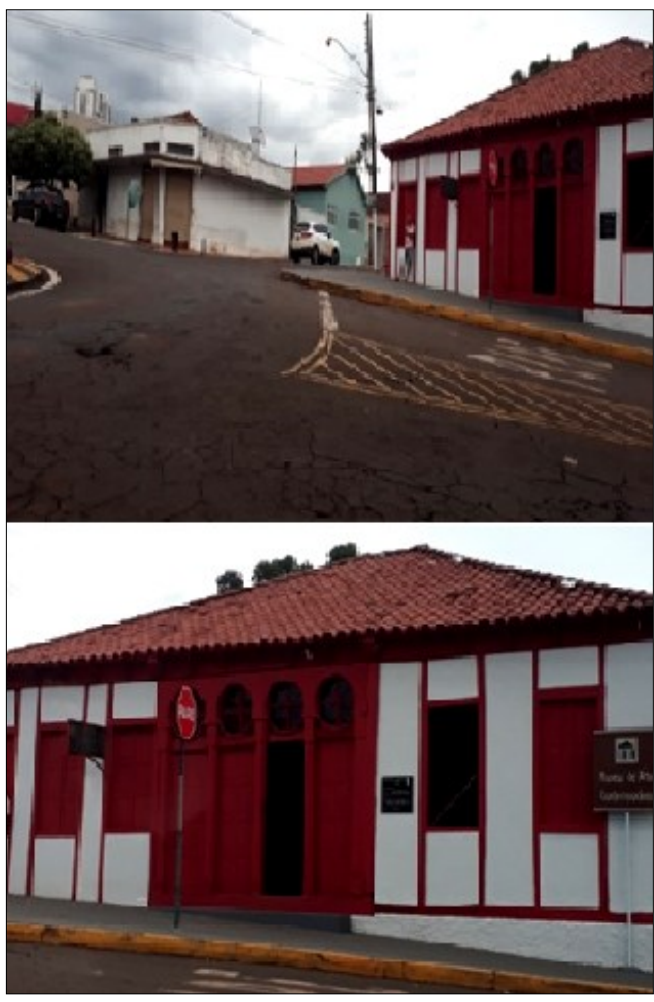

Fonte - PAIVA, P. B, 2018.

É possível afirmar que a paisagem se transforma de acordo com as necessidades da sociedade. As funções dos lugares também se modificam do mesmo modo, conforme Pinto Júnior, Menezes e Silva (2012, p. 41), "infelizmente, muitos desses edifícios foram demolidos ou descaracterizados profundamente", pois, é possível verificar que existe certo descaso do poder público com essas grandes estruturas históricas na cidade, visto que, as transformações na paisagem acontecem de acordo com a demanda da necessidade do capital.

Apesar dos impasses que essas construções de tempos passados enfrentam, é pertinente dizer que sua diversidade de contrastes arquitetônicos, ao ocupar o mesmo espaço que as construções da era moderna e tecnológica, é exemplo de que essas rugosidades estão ali presentes, resistindo, em meio a tantas transformações que vão surgindo conforme os anos vão se passando.

Dessa forma, a paisagem urbana demonstra o exemplo das transformações espaciais que vêm ocorrendo nos últimos tempos, e que, a partir das dinâmicas existentes no espaço urbano é que se considera possível encontrar tais rugosidades.

Nesse sentido, foi identificada a presença das rugosidades na paisagem da área de estudos, sendo elas estruturas arquitetônicas e históricas importantes para a compreensão do processo de transformação socioespacial, concordando com Alves, (2016 p. 64) "as rugosidades como um elemento importante, de remanescência natural, material e social".

\section{CONSIDERAÇÕES FINAIS}

A paisagem urbana configura-se em um espaço dinâmico com vários elementos diferentes. Dessa forma, conforme for evoluindo os tempos, se transforma de acordo com as necessidades da sociedade. Todavia, ressalta-se também que tal paisagem possui contradições, tempos, formas, cores e aparência em geral diferentes.

A paisagem urbana serve como exemplo das transformações espaciais que vêm ocorrendo nos últimos tempos. A partir dessa dinamicidade existente no espaço urbano, é que se considera possível encontrar 
rugosidades, que são as construções de épocas passadas, que ainda resistem ao tempo e estão presentes nessa paisagem que em seu entorno há construções que seguem outras formas arquitetônicas da atualidade.

Sobre a multifuncionalidade do centro da cidade, ressalta-se que este bairro é caracterizado por possuir diversidade de serviços, bem como residências e locais públicos, como as praças, por exemplo. A composição do comércio, juntamente com os bancos e as moradias encontradas nesse local mostra a variedade de formas e funções que podem ser encontradas nessa região. No caso do Centro Histórico, é possível ver esses atributos que contribuem para a heterogeneidade da paisagem urbana do bairro. Casas com arquiteturas coloniais, casas com alpendres, casas da contemporaneidade, variados tipos de comércio, bancos e, até mesmo, a forma com que os fluxos de veículos e pessoas são diferentes conforme o horário do dia, compõem essa multifuncionalidade.

Quanto à presença das rugosidades na paisagem urbana da cidade de Jataí, destaca-se que elas são memórias do passado que devem ser preservadas. Ao mesmo tempo em que o atual sistema capitalista incentiva, de certa forma, os processos de contato entre culturas e economias diversificadas, também contribui para o surgimento de diversas formas e funções de locais, e que muitas vezes resultam na construção de novas referências simbólicas ou mesmo da reelaboração de antigas. O que foi percebido durante a pesquisa, foram as adaptações na estrutura desses locais afim de preservar a sua arquitetura externa, ou seja a sua forma, mesmo tendo outra função, já que muitas dessas construções eram usadas como residências e estão sendo utilizadas como museus. Por isso que a paisagem e os seus usos se modificam de acordo com as necessidades da sociedade, a qual está em constante movimento e transformação.

Essas rugosidades possuem ao redor construções antigas e modernas, e por estarem todas localizadas em bairros considerados como o centro da cidade, é perceptível que o fluxo de carros e de pessoas seja constante, o que torna essas arquiteturas coloniais visíveis na paisagem. $O$ trabalho foi realizado a fim de contribuir com os estudos urbanos da cidade de Jataí - GO, bem como servir como fonte de conhecimento acerca do presente tema.

\section{AGRADECIMENTOS}

À CAPES pela bolsa de pesquisa de Mestrado Acadêmico em Geografia.

\section{REFERÊNCIAS}

ALVES, Maria do Carmo. Usos do Território e Rugosidades: fundamentos socioespaciais do patrimônio histórico do Estado do Ceará. Tese (Doutorado em Geografia Humana). Faculdade de Filosofia, Letras e Ciências Humanas da Universidade de São Paulo: São Paulo. 2016.

CARLOS, Ana Fani Alessandri. A Cidade. 8ª ed. São Paulo - SP: Contexto, 2009.

DAMIANI, Amélia Luisa. O lugar e a produção do cotidiano In: CARLOS, Ana Fani Alessandri. (org) Novos Caminhos da Geografia. São Paulo - SP: Contexto, 2002.

LUCHIARI, Maria Tereza Duarte Paes. A (re)significação da paisagem no período contemporâneo. In: ROSENDAHL, Zeny. CORREAA, Roberto Lobato. (orgs.). Paisagem, imaginário e espaço. Rio de Janeiro - RJ: Editora UERJ, 2001. p. 9 - 28.

MACHADO, José Roberto. Processos e formas espaciais no espaço urbano: reflexões acerca dos conceitos centro, área central, central, centralidade e descentralização. In: BOVO, Marcos Clair; TÖWS, Ricardo Luiz; COSTA, Fábio Rodrigues da. (orgs). Estudos urbanos em perspectivas: reflexões, escalas e desafios. Campo Mourão - PR: Editora da Fecilcam, 2013. p. 162 - 176.

MELO, Vera Mayrinck. Paisagem e simbolismo. In: In: ROSENDAHL, Zeny. CORREAA, Roberto Lobato. (orgs.). Paisagem, imaginário e espaço. Rio de Janeiro - RJ: Editora UERJ, 2001. p. 29 48.

PEREIRA, Aires José. Leituras de Paisagens Urbanas: Um estudo de Araguaína - TO. Tese (Doutorado em Geografia) - Instituto de Geografia, Universidade Federal de Uberlândia. Uberlândia MG, p. 312, 2013. 
PINTO JÚNIOR, Rafael Alves; MENEZES, Marcos Antonio de; SILVA, Adriano Freitas. Jatahy: espaços de morar (1880 - 1935). Goiânia - GO: Editora PUC Goiás, 2012.

SANTOS, Milton. A Natureza do Espaço. $4^{\mathrm{a}}$ ed. São Paulo - SP: Editora da USP, 2014.

SANTOS, Milton. Pensando o espaço do homem. $5^{\text {a }}$ ed. São Paulo: Editora da USP, 2007.

SOUZA, Marcelo Lopes de. Os conceitos fundamentais da pesquisa socioespacial. Rio de Janeiro: Bertrand Brasil, 2013.

SPOSITO, Maria Encarnação Beltrão. Novas formas comerciais e redefinição da Centralidade IntraUrbana. In: Textos e contextos para leituras geográficas de uma cidade de médio porte.

Presidente Prudente - SP: Pós-Geo/GASPPER, 2001. p. 235-254.

VENTURI, Luis Antonio Bittar. Ensaios Geográficos. São Paulo: Humanitas, 2008.

Recebido em: 26/03/2020

Aceito para publicação em: 19/10/2020 